\title{
The Use of Metaphor in Clinical Supervision
}

\author{
Douglas A. Guiffrida, Rachel Jordan, Stephan Saiz, and Kristin L. Barnes
}

UThe authors completed a critical review of the literature on the use of metaphor and the efficacy of metaphoric activities in clinical supervision. The authors conclude that these activities might assist students in understanding the process of becoming a counselor and facilitate students' case conceptualization skills. Cautions to consider when implementing metaphoric activities, limitations of research that has investigated the effectiveness of using metaphors in supervision, and suggestions for future research in this area are presented.

Metaphor, the Greek word meaning transfer, appears throughout the ages in stories designed to elicit growth or change, including biblical parables, myths, legends, and fairy tales (Campbell, 1988). One reason for the broad appeal of metaphor as a means of eliciting growth and change is that it allows new knowledge and ideas to be conveyed using frames of reference that are familiar to the learner (Langer, 1948). By relating a seemingly new idea to something the learner already knows, metaphors give familiarity to the unfamiliar, thus making new information seem less overwhelming and more easily understood (Campbell, 1988). Metaphors also allow people to ascribe affect to language by evoking past emotions (Campbell, 1988). Additionally, Langer (1948) asserted that the metaphoric process of thinking about and describing one thing in terms of another actually helps people create their own new ideas.

Because of the utility of metaphor in conveying thoughts and feelings and eliciting growth and change, it is not surprising that metaphor has been used by counselors for decades as a therapeutic tool (Barker, 1985; Barnat, 1977; Gordon, 1978; Martin, Cummings, \& Hallberg, 1992). Some of the most influential figures in counseling, including Sigmund Freud (1965), Rollo May (1991), Carl Jung (1961), Milton Erikson (Erikson \& Rossi, 1979), and Carl Rogers (1942), have asserted the importance of counselors using metaphors to facilitate client growth and development. In their review of the therapeutic metaphor literature, Lyddon, Clay, and Sparks (2001) noted that metaphors provide a method that counselors can use in several therapeutic functions, including (a) building relationships with clients, (b) accessing and symbolizing client emotions, (c) uncovering and challenging tacit client assumptions, (d) working with client resistance, and (e) introducing new frames of reference. According to S. B. Kopp (1971), counselors who recognize and use metaphors in their sessions allow clients to shed "a new light on the character of what is being described" (p. 17).

Recently, the use of metaphor has also been extended to the practice of clinical supervision, a critical component to the training and lifelong development of successful counselors (Bernard \& Goodyear, 1998). In their review of the supervision literature, Bernard and Goodyear recognized the potential of metaphor tofacilitate supervisee development; however, they also noted that many supervisors are not accustomed to introducing metaphors or metaphoric activities into the supervision session. Bernard and Goodyear suggested that supervisors who are unfamiliar with using metaphors could harness the power of metaphor by using metaphors and metaphoric activities that other supervisors have developed. The purpose of this article is to provide clinical supervisors with a description of the various metaphoric activities that can be used to enhance supervisee development. Additionally, we review research on the efficacy of using metaphors in supervision in order to (a) outline strengths and limitations of these techniques and (b) offer directions for future research in this area.

\section{- Literature Review}

A review of the supervision literature revealed several professional references in which metaphoric activities were suggested as a means for enhancing the supervision experience. These activities can be separated into one of two categories on the basis of their intended purpose. The first category emphasizes using metaphoric activities to help students understand the process of becoming a counselor; the second category of metaphoric supervisory activities is designed to facilitate supervisee case conceptualization skills. A description and critical review of each metaphoric activity is presented below.

\section{Understanding the Process of Becoming a Counselor}

Supervision is commonly conceptualized as a process that involves a progression through various developmental stages (Stoltenberg \& Delworth, 1987). At times, this process can be a painful and turbulent experience for the supervisee (Valadez

Garcia, 1998). In supervision, the supervisor often serves as a guide to assist supervisees in understanding the developmental process of becoming a counselor so that supervisee development is facilitated (Sommer \& Cox, 2003). Metaphor can be used as a tool for helping students understand this developmental process. We describe how techniques such as the use of Greek mythology, environmental metaphors, and drawing can be implemented to promote supervisee self-understanding and awareness.

\footnotetext{
Douglas A. Guiffrida and Rachel Jordan, Warner Graduate School of Education and Human Development, University of Rochester; Stephan Saiz, Community Counseling Program, The State University of New York at Plattsburgh; Kristin L. Barnes, Mental Health Counseling Program, St. John Fisher College. Correspondence concerning this article should be addressed to Douglas A. Guiffrida, Warner Graduate School of Education and Human Development. University of Rochester, PO Box 270425, Dewey Hall, Rochester, NY 14627 (e-mail Douglas.Guittrida@Rochesteredu orDGuiffrida @Warner.Rochester.edu).
}

2007 by the American Counseling Association. All rights reserved. 


\section{Greek Mythology}

According to Stoltenberg and Delworth's (1987) Integrated Development Model of Counselor Development, counselor trainees advance through three stages of development, with each stage reflecting progression in the areas of self and other awareness, motivation, and autonomy. Citing the frequent use of myth to describe phenomena in depth psychology, Sommer and Cox (2003) developed a method of using Greek mythology to facilitate counselor development by helping supervisees explore the ways mythological characters move through similar stages. In the story of Psyche and Eros, Psyche is sent by Aphrodite to complete four seemingly impossible tasks: sorting a large mound of jumbled seeds into piles, collecting fleece from golden rams, filling a flask with water that flowed from the highest peak, and retrieving a cask of beauty ointment from the underworld. Sommer and Cox proposed that each of these tasks parallels lessons found in supervision. Sorting a pile of seeds is comparable to sorting through personal values, and gathering golden fleece is related to supervisees' needs to claim their power. Filling the flask from the highest peak is meaningful for counseling students as they struggle to maintain perspective; journeying to the underworld educates beginning counselors to learn to say no. Sommer and Cox believed that sharing this interpretation with their supervisees would normalize the struggles commonly found in the counselor development process and would aid supervisees in conceptualizing their own developmental processes. By assisting students in recognizing and negotiating common developmental challenges, the myth-based metaphor provides the potential to facilitate student self-awareness, motivation, and autonomy.

In addition to supervisors sharing their interpretation of the story with their supervisees, Sommer and Cox (2003) emphasized the importance of allowing supervisees to develop their own interpretations of these and other stories, stating, "the beauty of story/myth is that others might find different, yet equally significant meanings that resonate for them" (p. 333). They believed that encouraging students to develop their own interpretations allows supervisors opportunities to understand their supervisees in new ways. Furthermore, they argued that sharing these interpretations during group supervision sessions would enrich discussions within the group. The authors noted that although research was needed to determine how to match relevant stories with supervisee issues and developmental stages, they believed that this technique provides an avenue for gaining insight into supervisees' values and priorities and offers a tool for enhancing the supervision process.

\section{The Environmental Metaphor}

Valadez and Garcia (1998) introduced a second way that supervisors can use metaphor to assist supervisees in conceptualizing their development as counselors. They proposed that using an environmental metaphor, such as layers of the atmosphere, can help supervisees better understand their supervision experience by allowing the supervisee to "conceptualize past evaluative experiences in a new and different light" (p. 103). In this activity, the authors focus on the evaluative component of supervision by conceptualizing the supervisor as the sun and the supervisee as a seed or sprout. Just as the sun's rays interact with the seed, the supervisor's evaluative comments may stimulate and awaken "innate, growth-capable elements" (Valadez \& Garcia, 1998, p. $94)$ in the supervisee. However, because of its intensity, the rays of the sun also have the potential to overstimulate and destroy the seed if adequate filtering mechanisms are not in place. Similarly, supervisor comments, especially those that are perceived as unfair or harsh by supervisees, can also hinder rather than stimulate supervisee development.

Valadez and Garcia (1998) drew parallels between the many layers of the earth's atmosphere, both visible and invisible, and the filtering layers supervisees need to allow them to absorb evaluative feedback in ways that produce growth. The authors maintained that it is essential for supervisees to become aware of the layers of their own defense systems, which have evolved from past evaluative experiences, so that they do not (a) become overly defensive or (b) project their past supervision experiences onto the current evaluative process. Valadez and Garcia believed that introducing this environmental metaphor early in the supervision process allows supervisors to stir up and awaken supervisees' past experiences and hidden feelings regarding evaluation and feedback. The authors asserted that this process is vital for supervisees so that they learn effectively from their new experiences. Moreover, the authors suggested that a second supervisor, who serves in a nonevaluative role, be introduced to the relationship, which, again using the metaphor of the earth's atmosphere, they referred to as "the moon" ( Valadez \& Garcia, 1998, p. 95). Just as the moon reflects the sun's light in a softer manner, the second supervisor can also reflect supervisor sentiments in a softer, nonevaluative way; this individual can also assist supervisees in exploring and processing their own reactions to the supervisor's feedback. Taken together, the authors believed that this combined process helps students understand the evaluative process of supervision and helps ameliorate the anxiety that is often related to evaluation.

\section{Metaphoric Drawing Activities}

Using drawing as a communication tool can also assist supervisees in understanding the process of becoming a counselor. Fall and Sutton (2004) offered an example of a structured metaphoric drawing activity in which supervisees are asked at the midsemester point of their field experience to draw pictures that depict the students perceptions of their stage of development in becoming a counselor. Students are given colored pencils, markers, crayons, and large pieces of paper and are instructed to complete the activity in 15 minutes. When the semester ends 7 weeks later, the students complete the same activity and, within small groups, compare the later pictures to the pictures they had completed at midsemester. Fall and Sutton reported that their students believed the activity helped them identify issues within their experiences that were previously unrecognized, thus facilitating their ability to conceptualize these struggles and triumphs within the context of their own developmental process of becoming a counselor. In addition, they asserted that the activity allows professors to learn much more about the 
The Use of Metaphor in Clinical Supervision

supervisees and their stage of development as counselors than if they had asked them direct questions. The authors concluded that the drawing activity was "a valuable use of group supervision time for practicum students" (Fall \& Sutton, p. 61).

\section{r'-acilitating Case Conceptualization Skills}

Another important objective of supervision is to help supervisees develop case conceptualization skills (Bernard, 1979; Loganbill \& Stoltenberg, 1983; Young \& Borders, 1999). According to Stone and Amundson ( I 989), assisting students to conceptualize their cases during supervision not only allows students to develop practical client treatment strategies, but also allows them to generate hypotheses for future cases that are similar. The following are illustrations and preliminary findings regarding the use of metaphoric stories, metaphoric drawing, and sand trays for facilitating supervisee case conceptualization skills.

\section{Metaphoric Stories}

In one of the first published research studies on the impact of intentional use of metaphor in supervision, Young and Borders (1998) investigated 30 first-year master's-level counselor education students' abilities to develop clinical hypotheses after viewing small segments of supervision sessions. Participants were randomly exposed to one of two 9-minute treatment videotapes. In the first videotape, a supervisor used a narrative analogy metaphor to help the supervi see interpret a specific clinical issue related to the case. The metaphor, which was derived using characteristics of effective metaphors found in counseling literature, related the supervisee's situation to that of a monkey that, while reaching into a jar to grab a piece of fruit, cannot escape from the jar because the fist he makes is too large to fit through the opening of the jar. In the second tape, a supervisor used literal communication without using metaphor to clarify clinical issues. After viewing the tape, participants in both groups completed measures assessing case conceptualization skill and perceptions of the supervision experience. The authors hypothesized that the students who viewed the segment in which the supervisor used a metaphor would develop a more complete hypothesis regarding the case. Their results, however, indicated that a single exposure to the tapes had no significant impact on students' perception of the supervisors or their ability to generate hypotheses. The authors noted that a major limitation of the study was that students were exposed to metaphoric analogy only one time before completing the measure and that they were given very limited exposure to the treatment conditions. Another limitation was that the metaphor was used in general terms and was not used to address specific issues within a supervision session.

To address the limitations of the aforementioned study, Young and Borders (1999) conducted a follow-up study using a more naturalistic setting. To investigate how a supervisor's intentional use of metaphor affected supervisee conceptualization skills, a case study design was implemented, using multiple measures. Specifically, the investigators sought to understand what impact the intentional use of metaphor had on (a) supervisees' recall of supervision events,(b) supervisees' perceptions of the effectiveness of Journal of Counseling \& Development m Fall 2007 Volume 85 supervision, and (c) supervisees' ability to conceptualize clinical situations. Twelve supervisees were exposed to metaphor by their supervisors in actual supervision sessions. The same supervisors avoided all use of metaphor while working with the control group.

Results of the study suggested that although the use of metaphor helped supervisees remember important supervision events, metaphor did not appear to have a more significant impact on event recall than did the control group conditions. In addition, the statistical analyses did not indicate that the metaphor group developed more sophisticated case conceptualization skills than did the nonmetaphor group. The authors, however, noted several limitations of the study that may have contributed to the lack of empirical support for the use of metaphor. First, because the study was conducted in a naturalistic setting, the authors were unable to control for confounding variables such as differences in internship settings. Second, the small sample size limited the chance of producing statistical significance because of low statistical power. Third, they hypothesized that their assessment instrument, which did not show high interrater agreement for the scoring categories, may have failed to discern subtle or sensitive differences among the participants (Young \& Borders, 1999).

Although their quantitative analyses produced nonsignificant findings, Young and Borders (1999) noted some qualitative evidence regarding the benefit of metaphor with some supervisees. Several of the participants described an increase in their use of metaphor within their client sessions as a result of their metaphor-based supervision experiences. Thus, parallel learning occurred through modeling. Additionally, the authors noted that the metaphors used in the sessions often "provided an underlying theme for the supervision process which was discussed throughout the semester, allowing the supervisee and supervisor to develop a shared language for the supervisee's experience" (Young \& Borders, 1999, p. 147). Therefore, the results suggested that although it is difficult to assess the impact of metaphor on case conceptualization, it is possible that metaphor has the potential to enhance the conceptualization skills of some supervisees.

\section{Metaphoric Drawing Activities}

In addition to helping supervisees conceptualize their development as counselors, metaphoric drawing exercises have also been presented as a means of enhancing supervisees' case conceptualization skills. Amundson (1988) asserted that the metaphoric drawing process is similar to the process of case conceptualization in that both processes involve the synthesis of a variety of cognitive, behavioral, emotional, and interpersonal information to arrive at new conclusions or levels of awareness. As a metaphoric technique in supervision, drawing allows counselors to assemble "a complex array of information into a relatively simple visual image" (Amundson, 1988, p. 391). In the metaphoric case drawing method presented by Amundson, supervisees are asked to draw a picture or make a collage that illustrates, metaphorically, their conception of the client. Supervisees are also asked to incorporate how they envision the case proceeding. Amundson 
noted that if a more thorough, complete conceptualization is 
needed, supervisees should complete the drawings outside of the supervision group session, where they may take their time thinking about and constructing the metaphor. However, if the supervisee conceptualization requires immediate attention, a relatively quick sketch of the case can be completed during the group session. After completing their drawings, supervisees share their conceptualizations with a supervision group in a stepwise process. They begin by using the picture to illustrate and summarize their cases. Then, the group members discuss the case. In the third step, the focus of the discussion shifts from discussing the client to focusing on the relationship between the client and the supervisee. The discussion concludes by asking the supervisee to describe how the drawing could have been altered to reflect a different counseling approach or intervention.

To illustrate the case conceptualization drawing technique, Amundson (1988) provided an example of a supervisee who drew a picture of her client pushing a load up a steep hill, with obstacles everywhere, while various angels hovered overhead pointing the way. When the supervisee presented this drawing during her small- group supervision session, her peers raised several questions and issues for her to consider. The discussion not only helped the supervisee gain clarity regarding the case, but also gave her an opportunity to develop new intervention approaches for assisting the client. Amundson concluded that the approach was useful for encouraging case conceptualization skills and facilitating meaningful conversations in small-group supervision.

In an attempt to examine the usefulness of the metaphoric case drawing method, Stone and Amundson (1989) compared the drawing technique to traditional verbal case debriefing with seven counselor interns at a community crisis center. Supervisees in the traditional verbal case debriefing group did not complete any written forms or drawings and, instead, followed a question-and-answer discussion format that resembled a Socratic or dialectical method of "thesis-antithesis-synthesis" (Stone \& Amundson, 1989, p. 361). These discussions focused on supervisees' assessments of their clients' presenting problems (i.e., affective, behavioral, cognitive, and systemic components) and analyses of counselor techniques and intervention strategies. Discussions in the verbal case debriefing sessions also focused on supervisee assessments of interpersonal and relationship factors that may have had an impact on the session. Supervisees using the metaphoric case drawing method were asked to translate their thoughts about their sessions into a metaphoric drawing. Supervisees were free to draw any form they chose, which included abstract symbols, line drawings, and combinations of words and pictures. The pictures then became the focus of a supervisee-directed debriefing session where, us-Mg the format described by Amundson (1988), the supervisees presented their cases in small supervision groups.

When the supervision experiences ended, both groups of supervisees and their supervisors completed a 39-item questionnaire to evaluate how well the supervision sessions addressed the concerns of the client, the development of the counselor, the client-counselor relationship, the counselor goals, and the perceived value of the supervision session. Additionally,qualitative data, including clinical case notes, filmed segments of supervision sessions, transcripts, and drawings from the metaphoric case drawing sessions, were collected and analyzed (Stone \& Amundson, 1989).

Analysis of variance revealed greater gains in understanding across all five subscales (Addressing Concerns of Clients, Development of the Counselor, Client/Counselor Relationship, Counselor Goals, and Perceived Value of Supervision) from the metaphor group when compared with the mean scores of students using the traditional supervision method. The results also revealed that participants in the metaphoric drawing group met with their supervisors on average $20 \%$ less often, suggesting that the technique might have been more efficient than the traditional verbal method. Moreover, the analysis revealed that the supervisees who used the metaphoric drawing method tended to present more emotionally charged cases (i.e., suicide, depression, relationship conflicts) and frustrating cases (i.e., chronic clients) than those presented by supervisees in the verbal supervision group. Although the investigators noted several limitations of the study, including small sample size $(N=7)$ and lack of extensive controls (because the investigation was conducted in a real-world internship setting), they concluded that the metaphoric case drawing method was potentially a powerful means for facilitating case conceptualization skills in a time-limited, small-group setting, especially when conceptualizing cases related to depression, suicide, and relationship problems (Stone \& Amundson, 1989).

Ishiyama (1988) supported the effectiveness of Amundson's (1988) case conceptualization drawing technique and expanded on it by offering more specific instructions and a more operationalized case conceptualization procedure. Ishiyama suggested that the supervisor begin the metaphoric drawing activity by asking supervisees to reflect, in writing, on a specific problematic counseling session or case. To assist supervisees in this reflective process, Ishiyama suggested that supervisors ask their supervisees to complete the following six sentence stems: "What I see as the client's main concern is . . .," "The way the client interacted with me is . . , " "What I was trying to do in this session is ...," "What I felt or thought about myself as a counselor in this session is ., ," "The way the session went is . . .," and "What I think the client gained from the session is . . " (p. 155). After completing this activity, supervisees are then asked to respond to the following second set of sentence stems that are designed to encourage metaphoric thinking: "The way I perceived the client with his or her concern may be characterized by a metaphor or an image Ike ," "The way the client responded to me and felt toward me during this session may be characterized by a metaphor or an image like. . ," "The way I conducted myself during this session may be characterized by a metaphor or image like ...," and "The way this session went may be characterized by a metaphor or image like ..." (Ishiyama, 1988, p. 156). Next, supervisees are asked to illustrate the case by drawing it, using metaphoric images and symbols, Finally, supervisees are asked to share their drawings in visual case conceptualization discussions that occur with other trainees and their supervisor. In these small-group discussions, the presenter, 
rather than the supervisor, takes the lead in facilitating the conversation. Group members are encouraged to assist the presenter in developing the case conceptualization further by asking questions, expressing empathic understanding of the issues, and extending the presenter's metaphor. Ishiruna suggested that after they have completed the activity, supervisees could change the drawings to reflect new insight that occurred as a result of the discussion and to document how supervisees' conceptualizations have changed over time. Moreover, the author indicated that supervisors could share their drawings with their clients to generate discussions about client issues or the counselor-client relationship.

To test the effectiveness of the enhanced metaphoric drawing activity Ishiyama (1988) asked 19 undergraduate counseling students who participated in both the metaphoric drawing activity and a more traditional verbal case conceptualization procedure to rate the approaches, using a 9-point scale. Participants also provided written explanations for their ratings. The results showed that 13 of the 19 participants found the metaphoric drawing activity to be superior to the nonvisual method in encouraging "deeper understanding of the client, the helper, the client-helper relationship, and the counseling goals to strive towards" (Ishiyama, 1988, p. 159). Three of the participants were more neutral and described value in both approaches. Two participants preferred the nonvisual method because the process was one that was more familiar to them. Additionally, these 2 participants described themselves as having difficulty developing their own metaphors. The qualitative data indicated that the metaphoric drawing activity was particularly helpful to students who were visual learners or who preferred an artistic medium of expression. Although the author cautioned that the activity permitted some students to become more focused on self-exploration than client case conceptualization, Ishiyama concluded that, in general, the metaphoric drawing activity increased case conceptualization skills and enhanced case presentation discussions.

Saiz and Guiffrida (2001) presented another metaphoric drawing technique that supervisors can use to facilitate supervisee case conceptualization skills. The activity labeled "Where am I?" is based on the procedures outlined by R. R. Kopp (1995) for using metaphors in therapy. To begin, the supervisor draws a stick figure on a piece of blank paper to represent the supervisee's client. The supervisor then asks the supervisee to place an $\mathrm{X}$ on the paper to indicate where the supervisee feels he or she is in relation to the client. The supervisor explains that the $\mathrm{X}$ can appear above the client, below the client, on either side of the client, or any other place that the supervisee feels would accurately describe the context of his or her relationship with the client.

Next, the supervisor assists the supervisee in exploring and understanding the dynamics leading to the supervisee's placement of the X (Saiz \& Guiffrida, 2001). The supervisor begins by asking the supervisee to use a metaphor to describe what it is like to be in the place they indicated on their drawing. Examples of metaphoric responses to this question include "It is like carrying a heavy load on my shoulders" or "I feel like the client is weighing me clown." If the supervisee experiences difficulty formulating a metaphoric response to the question, the supervisor can assist by asking a series of follow-upquestions relative to the supervisee's position. For example, if Journal of Counseling \& Development Fall 2007 a Volume 85 supervisees have drawn themselves above the client, the supervisor could ask if they felt that they were teaching or directing the client or if they felt superior, in some way, to the client. Supervisees who placed themselves below the client could be questioned regarding whether they felt that they were carrying or supporting the client or whether they somehow felt inferior to or unworthy of the client. Supervisees who placed themselves behind the client could be asked if they felt that they were pushing the client or if they were having a hard time keeping up with the client.

After the supervisee has developed a metaphor to describe her or his relationship with the client, the supervisor helps the supervisee expand the metaphoric image by asking questions that are designed to facilitate an understanding of sensory images related to her or his work with the client. To begin, the supervisor asks the supervisee to expand her or his metaphoric image. For example, the supervisor could ask questions geared toward exploring the visual (e.g., What do you see when you think about yourself being below this client?) or auditory sensations (e.g., What sounds do you notice?) experienced while immersed in the metaphoric image. Questions regarding affective and cognitive reactions found in the metaphor (e.g., What feelings or thoughts surround you in the metaphor?) can also be used. To help the supervisee understand how systemic and contextual factors affect the client's situation, the supervisor can use questions such as "Who else is involved in the metaphor" and "Where might you place these other people in relation to you and the client?" Additionally, the supervisor can also use the metaphoric image to explore the supervisee's perceptions of her or his client's experience in the metaphor by asking, "How do you think your client feels about you being positioned below her or him in the relationship?"

Finally, the supervisor invites the supervisee to change the metaphor in any way she or he feels necessary to better assist the client by asking, "If you could make some change to the metaphor, what might it be?" After the supervisee elaborates on the various components of the metaphoric image, the supervisor asks the supervisee to use the metaphor to assist her or him in (a) formulating a new conceptualization of the client's issues, (b) understanding his or her relationship with the client, and

(c) recognizing how the metaphor and the changes made to it can inform future directions with the client.

Although this activity can be useful with supervisees at any stage in their development, Saiz and Guiffrida (2001) believed that the activity was particularly beneficial in facilitating supervisee conceptualization skills during the impasse that many supervisees experience early in their clinical experiences. In addition to broadening supervisee case conceptualizations skills, Saiz and Guiffrida asserted that this activity may empower supervisees to find their own solutions to their difficulties rather than rely on their supervisor for answers. Additionally, the activity allows the supervisor to gain access to the supervisee's belief system in a way that is nonthreatening and respectful of supervisees (Saiz \& Guiffrida, 2001). 
in their first practicum. During the 4th week of their super $\backslash$ sion,

Another metaphoric technique used to enhance supervisee conceptualization skills is the use of the sand tray, which has long been used in child therapy as a means of expression and working through conscious and unconscious thoughts and feelings in therapy (Ammann, 1991; Vinturella \& James, 1987). Similar to the process of sand tray therapy, use of the sand tray in supervision involves the supervisor offering various miniature elements used in the sand tray, including storybook characters, animals, vehicles, and so on, and a small sandbox, and asking the supervisee to use the figures to depict, within the sand tray, themes, issues, and relationships in their clients' lives. Fall and Sutton (2004) asserted that using the sand tray in supervision lowers supervisee defenses, fosters supervisees' creativity and right brain activity, and enhances their case conceptualization skills by allowing supervisees to visually represent their cases. Similarly, Markos and Hyatt (1999) stated that asking supervisees to depict their clients' issues and relationships in the sand can assist supervisees in gaining new insight into their clients' problems. Furthermore, Markos and Hyatt believed that having supervisees enact their sessions using figures from the sand assists supervisees in unlocking unconscious thoughts about the therapeutic relationship.

In outlining the effectiveness of the sand tray approach, Markos and Hyatt (1999) pointed to one supervision session in which a supervisee chose a figure to represent herself that was much smaller than the one she chose for her client. When asked by the supervisor about this, the supervisee realized that she felt nervous and "small" about dealing with such a difficult case. Similarly, Fall and Sutton (2004) illustrated how the use of the sand tray allowed a supervisee new insight regarding why she had previously been intimidated by her client. Both Markos and Hyatt and Fall and Sutton suggested that supervisees who use the sand tray are often able to conceptualize their client cases and their relationships with their supervisors in ways that could not be achieved by traditional, verbal case discussions. Markos and Hyatt also asserted that using the sand tray in supervision creates a parallel learning process, meaning the activity assisted students in learning how to use the sand tray in their own work with clients. Finally, Barnes (2004) suggested that the use of a sand tray as a vehicle for communication in group supervision can facilitate the group development process; when her supervisory groups used the sand tray to provide feedback to one another, Barnes reported that the feedback was usually more thoughtful, challenging, and honest than when group members were asked to provide this feedback using verbal methods alone.

Although most of the support regarding the power of the sand tray in supervision comes from personal anecdotes, research from one small empirical study provides initial support regarding the effectiveness of using the sand tray in supervision. Markos, Coker, and Jones (2004) conducted a pilot study using 6 female counseling students who were enrolled the participants were divided into two equal groups: of group received supervision using the program's tradition technique, which included watching their sessions with the supervisors and discussing their strengths and areas in need improvement. The second group participated in the sand try activity. After the session, both groups of students complete the Supervisory Working Alliance Inventory (Efstation, Pa ton, \& Kardash, 1990) and two scales designed to measu rapport and client focus. The results did not reveal significa differences regarding supervisees' perceptions of the quali: of their supervision, indicating that sand play was perceive to be as effective a procedure as their traditional supervisic modality. However, supervisees who participated in the sar tray method scored higher on their conceptualization of the cases. Although Markos et al. noted that more research w needed with larger samples to confirm these findings, the results suggest initial support for the potential of the sand try to enhance supervisee case conceptualization skills.

\section{EConclusions}

The results of this literature review indicate that metaphor activities can provide a valuable tool for facilitating supervise growth and development. One way in which metaphoric activ ties appear to be particularly useful is in helping supervise( understand the process of becoming a counselor. Althoug this assertion has not been validated by research, anecdot, evidence suggests that supervisors who use metaphoric a4 tivities such as Greek mythology (Sommer \& Cox, 2003 environmental metaphors (Valadez \& Garcia, 1998), an metaphoric drawing activities (Fall \& Sutton, 2004) encou age supervisees to (a) think critically about where they are $i$ relation to their goals and (b) use past learning experiences $t$ conceptualize their unique developmental processes.

Additionally, anecdotal evidence and limited research suppo the efficacy of metaphoric activities such as metaphoric stone (Young \& Borders, 1999), metaphoric drawing (Amundsoi 1988; Ishiyama, 1988; Saiz \& Guiffrida, 2001), and the san tray (Barnes, 2004; Fall \& Sutton, 2004; Markos \& Hyatt, 199' in facilitating case conceptualization skills among supervisee Benefits associated with these metaphoric activities include a lowing supervisors and supervisees to develop a shared languag with which to conceptualize cases (Young \& Borders, 1999 helping supervisees think about their interactions with clients in new light (Amundson, 1988), facilitating a deeper understandin of the client-counselor and supervisor-supervisee relationshi in supervisees (Ishiyama, 1988), and encouraging students t find their own solutions to problems rather than relying on the supervisors for answers (Saiz \& Guiffrida, 2001). Additionalt research suggests that metaphoric activities can encourage sti. dents to share more emotionally charged and frustrating cases an in less time than traditional supervisory methods allow (Ston \& Amundson, 1989). Moreover, it is possible that supervisee who are exposed to metaphors during their supervision sessio

Journal of Counseling \& Development n Fall 2007 a 
are likely to integrate metaphors into their own work with clients (Barnes, 2004; Fall \& Sutton, 2004; Young \& Borders, 1999).

The use of metaphor in clinical supervision offers great potential for facilitating supervisee growth and development. Readers are cautioned, however, to regard the limitations of these activities and the research that has investigated the effectiveness of metaphor in supervision. First, the success of metaphoric activities depends on how amenable the supervisee is to the approach. Supervisees who are unable to think abstractly or to integrate artistic thinking and expression into their discourse may express frustration and resistance to using metaphoric activities during supervision (lshiyama, 1988). In these instances, supervisors may consider it useful to offer trainees alternative, nonmetaphoric ways of communicating, particularly when the metaphoric activity is first presented as a supervision intervention. Supervisors may also find it useful to model conceptualizing cases through metaphor by presenting their own metaphoric stories, art work, or sand trays to the supervisee.

Second, the success of metaphoric activities in clinical supervision also appears to be related to the supervisor's level of skill and comfort in developing and using metaphors in appropriate ways that resonate with supervisees. Supervisors just beginning to use metaphors may want to seek supervision of their own supervision activities. Supervisors may also want to solicit consistent feedback from supervisees about the impact of their interventions on the supervision process.

Third, the efficacy of metaphoric activities is supported largely by anecdotal evidence. The small amount of research that has been conducted has suffered from methodological problems, including very small sample sizes, inconsistent or unknown interrater reliability in dependent measures, and lack of control of potentially confounding variables that limit the internal validity. Future quantitative research should address the aforementioned methodological issues both in controlled experimental conditions and in more naturalistic settings. In addition, researchers should explore the impact of the use of metaphors in supervision on supervisee and supervisor development, along with their associated processes, including counseling skill development, self-efficacy, and autonomy.

Furthermore, several of the authors presented in this article described the use of metaphoric activities in group supervision (Amundson, 1988; Barnes, 2004; Sommer \& Cox, 2003), yet little is known about the impact of these activities on the development of supervisory group process variables (e.g., group cohesion, feedback delivery, the potential for vicarious learning). Each of these areas of research is needed to expand the understanding of the potential that metaphor has on enhancing the group supervision process.

Finally, although quantitative research has been useful in identifying some of the variables necessary to facilitate supervisee development when metaphor is used, the literature reviewed in this article suggests that it is difficult to fully isolate supervisee or supervisor characteristics that lead to the successful use of metaphor in experimental or controlled studies. Thus, it is likely that more qualitative research is needed to understand the conditions under which metaphors can besuccessfully introduced as a means of facilitating supervisee Journal of Counseling \& Development $\square$ Fall 2007 a Volume 85 growth and development. Such research should (a) include supervisors who are comfortable using their own metaphors and metaphoric activities, (b) be conducted in naturalistic settings, and (c) seek to capture the perspectives of supervi sees regarding the interventions. Qualitative research of this nature will assist supervisors and researchers in understanding the complex and subtle characteristics and dynamics necessary to successfully introduce metaphor into the supervision session.

\section{RReferences}

Ammann R. (1991). Sandplay Chicago: Open Court.

Amundson, N. E. (1988). The use of metaphor and drawings in case conceptualization. Journal of Counseling and Development, 66, 391-393.

Barker, P. (1985). Using metaphors in psychotherapy. New York: Brunner/Mazel.

Bamat, M. R. (1977). Spontaneous supervisory metaphor in the resolution of trainee anxiety. Professional Psychology, 8, 307-315.

Barnes, K. L. (2004, October). Playful supervision: Using sand and drawing metaphors to enhance the supervisory process. Paper presented at the North Central Association for Counselor Education and Supervision annual meeting, St. Louis, MO.

Bernard, J. M. (1979). Supervisor training: A discrimination model. Counselor Education and Supervision, 19, 60-69.

Bernard, J. M., \& Goodyear, R. K. (1998). Fundamentals of clinical supervision. Needham Heights, MA: Allyn \& Bacon.

Campbell, J. (1988). The power of myth. New York: Doubleday. Efstation,

J. E, Patton, M. J., \& Kardash, C. M. (1990). Measuring the working alliance in counselor supervision. Journal of Counseling Psychology, 37, 322-329.

Erikson, M., \& Rossi, E. (1979). Hypnotherapy casebook New York: Irvington.

Fall, M., \& Sutton, J. M. (2004). Clinical supervision: A handbook for practitioners. Boston: Pearson Education.

Freud S. (1965). The interpretation of dreams. New York: Avon. Gordon. D. (1978). Therapeutic metaphors. Cupertino, CA: Meta. lshiyama, F I.

(1988). A model of visual case processing using metaphors and drawings. Counselor Education and Supervision, 28, 153-161.

Jung, C. (1961). Memories, dreams and reflections. New York: Vintage Books.

Kopp. R. R. (1995). Metaphor therapy: Using client-generated metaphors in psychotherapy. Bristol, PA: Brunner/Mazel.

Kopp, S. B. (1971). Gum: Metaphors from a psychotherapist. Palo Alto, CA: Science \& Behavior Books.

Langer, S. K. (1948). Philosophy in a new key: A study of the symbolism of reason, rite and art. New York: Brunner/Mazel.

Loganbill, C., \& Stoltenberg, C. (1983). The case conceptualization format: A training device for practicum. Counselor Education and Supervision, 22, 235-241.

Lyddon, W. J., Clay, A. L., \& Sparks, C. L. (2001). Metaphor and change in counseling. Journal of Counseling \& Development, 79, 269-274.

Markos, P. A., Coker, K., \& Jones, P (2004, April). Play or supervision? Using sandtray with beginning practicum students. Paper presented at the American Counseling Association world conference, Kansas City, MO.

Markos, P A., \& Hyatt, C. J. (1999). Play or supervision? Using sandtray with beginning practicum students. Guidance and Counseling 14, 3-6.

Martin, J., Cummings, A. L., \& Hallberg, E. T. (1992). Therapists' intentional use of metaphor: Memorability, clinical impact and possible epistemic/motivational functions. Journal of Consulting and Clinical Psychology 60, 143-145. 

Mifflin.

Saiz, S. G., \& Guiffrida, D. A. (2001, October). The use of metaphor in the supervision of counselor education students. Paper presented at the North Atlantic region of the Association for Counselor Education and Supervision annual meeting, University of Massachusetts-Amherst.

Sommer, C. A., \& Cox, J. A. (2003). Using Greek mythology as a metaphor to enhance supervision. Counselor Education and Supervision, 42, 326-335.

Stoltenberg, C., \& Delworth, U. (1987). Supervising counselors and therapists. San Francisco: Jossey-Bass.

Stone, D., \& Amundson, N. (1989). Counselor supervision: An explor

Valadez, A. A., \& Garcia, J. L. (1998). In a different light: An environmental metaphor of counselor supervision. Texas Counseling .4ssociation Journal, 26, 92-106.

Vinturella, L., \& James, R. (1987). Sand play A therapeutic medium wid children. Elementary School Guidance and Counseling 21, 229-238.

Young J. S., \& Borders, D. L. (1998). The impact of metaphor on clinical hypothesis formation and perceived supervisor characteristics Counselor Education and Supervision, 37,238-256.

Young, J. S., \& Borders, D. L. (1999). The intentional use of metapho! in counseling supervision. Clinical Supervisor, 18, 137-149. 